INTERNATIONAL JOURNAL
PHARMACEUTICAL SCIENCES
RESEARCI
RESTI

Received on 27 March 2019; received in revised form, 02 July 2019; accepted, 06 November 2019; published 01 January 2020

\title{
STABILITY INDICATING METHOD DEVELOPMENT AND VALIDATION FOR THE ESTIMATION OF ERTUGLIFLOZIN AND METFORMIN IN BULK AND PHARMACEUTICAL DOSAGE FORM BY ULTRA PERFORMANCE LIQUID CHROMATOGRAPHY
}

V. Mohan Goud and G. Swapna *

Department of Pharmaceutical Analysis, Joginpally B. R. Pharmacy College, Yenkapally, Moinabad, Ranga Reddy, Hyderabad - 500075, Telangana, India.

Keywords:

Ertugliflozin,

Metformin, UPLC, Validation

Correspondence to Author:

Dr. V. Mohan Goud

Associate Professor \& Head, Department of Pharmaceutical Analysis, Joginpally B. R. Pharmacy

College, Yenkapally, Moinabad,

Ranga Reddy, Hyderabad - 500075,

Telangana, India.

E-mail: mohanvanga@yahoo.com
ABSTRACT: A simple, accurate, precise method was developed for the simultaneous estimation of the Ertugliflozin and Metformin in Tablet dosage form. For the method development, Chromatogram was run through HSS C18 $(100 \times 2.1 \mathrm{~mm}, 1.7 \mu)$ column at a flow rate of $0.3 \mathrm{ml} / \mathrm{min}$. and buffer used in this method was Ortho Phosphoric Acid buffer. The temperature was maintained at $30{ }^{\circ} \mathrm{C}$. The optimized wavelength selected was $240 \mathrm{~nm}$. The retention time of Ertugliflozin and Metformin was found to be $0.736 \mathrm{~min}$ and 1.286 min. \% RSD of the Ertugliflozin and Metformin were and found to be 0.8 and 0.9 respectively. \% Recovery was obtained as $100.98 \%$ and $99.81 \%$ for Ertugliflozin and Metformin, respectively. LOD, LOQ values obtained from regression equations of Ertugliflozin and Metformin were $0.02 \mu \mathrm{g} / \mathrm{ml}$, $0.08 \mu \mathrm{g} / \mathrm{ml}$ and $1.04 \mu / \mathrm{ml}, 3016 \mu \mathrm{g} / \mathrm{ml}$ respectively. The regression equation of validated method for Ertugliflozin is $y=4132 . x+239.4$ and $y=3921 . x+$ 4097 of Metformin, respectively. Retention times were decreased so that run time was decreased, the developed method was simple and economical that can be adopted in regular Quality control test in Industries.
INTRODUCTION: Ertugliflozin belongs to the class of potent and selective inhibitors of the sodium-dependent glucose co-transporters, more specifically type 2 which is responsible for about $90 \%$ of the glucose reabsorption from glomerulus ${ }^{1-}$ 4. Metformin is an oral antidiabetic drug in the biguanide class ${ }^{5-7}$. It is the first-line drug of choice for the treatment of type 2 diabetes. It is also used in the treatment of polycystic ovary syndrome and has been investigated for other diseases where insulin resistance may be an important factor.

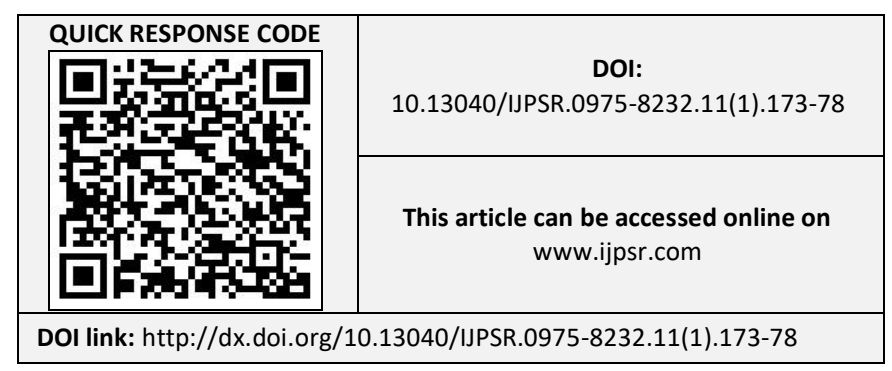

Metformin works by suppressing glucose production by the liver.
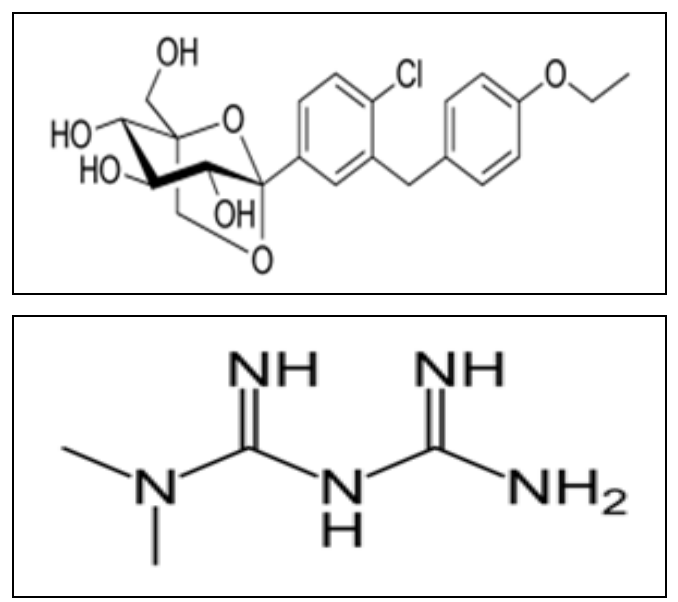

FIG. 1: STRUCTURES FOR ERTUGLIFLOZIN AND METFORMIN

Literature review ${ }^{10-14}$ reveals that different methods RP-HPLC, UV, LCMS for its analysis in 
formulations. Hence, our present plan is to develop a new, sensitive, robust \& accurate method for its analysis in the formulation, after a detailed study, a new UPLC method was decided to be developed and validated as per ICH norms ${ }^{15-16}$.

\section{MATERIALS AND METHODS:}

Instruments Used: Electronics Balance-Denver, pH meter -BVK enterprises, India, Ultra sonicatorBVK enterprises, WATERS UPLC 2695 SYSTEM equipped with quaternary pumps, Photo Diode Array detector, and Autosampler integrated with Empower 2 Software. UV-VIS spectrophotometer PG Instruments T60 with special bandwidth of 2 $\mathrm{mm}$ and $10 \mathrm{~mm}$ and matched quartz cells integrated with UV win 6 Software was used for measuring absorbances of AMT and LFT solutions.

Drug Samples: Ertugliflozin and Metformin pure drugs (API), Combination Ertugliflozin, and Metformin tablets (Segluromet).

Reagents and Solutions: Distilled water, Acetonitrile, Phosphate buffer, Methanol, Orthophosphoric acid [All are HPLC grade], Potassium dehydrogenate orthophosphate buffer [AR].

\section{Analytical Methodology:}

Diluent: Based upon the solubility of the drugs, diluent was selected, acetonitrile, and water taken in the ratio of 50:50.

Preparation of Standard Stock Solutions: Accurately weighed $3.75 \mathrm{mg}$ of Ertugliflozin, 250 $\mathrm{mg}$ of Metformin, and transferred to a $50 \mathrm{ml}$ volumetric flask. $3 / 4^{\text {th }}$ of diluents were added to the flask and sonicated for 10 min. Flask was made up of diluents and labeled as Standard stock solution $(5000 \mu \mathrm{g} / \mathrm{ml}$ of Ertugliflozin and $75 \mu \mathrm{g} / \mathrm{ml}$ Metformin).
Preparation of Standard Working Solutions (100\% Solution): $1 \mathrm{ml}$ from each stock solution was pipetted out and taken into a $10 \mathrm{ml}$ volumetric flask and made up with diluent $(500 \mu \mathrm{g} / \mathrm{ml}$ of Ertugliflozin and $7.5 \mu \mathrm{g} / \mathrm{ml}$ of Metformin).

Preparation of Sample Stock Solutions: 10 tablets were weighed, and the average weight of each tablet was calculated, then the weight equivalent to 1 tablet was transferred into a $100 \mathrm{ml}$ volumetric flask, $50 \mathrm{ml}$ of diluents was added and sonicated for $25 \mathrm{~min}$, further the volume was made up with diluent and filtered by HPLC filters (5000 $\mu \mathrm{g} / \mathrm{ml}$ of Ertugliflozin and $75 \mu \mathrm{g} / \mathrm{ml}$ of Metformin).

Preparation of Sample Working Solutions (100\% Solution): $1 \mathrm{ml}$ of filtered sample stock solution was transferred to a $10 \mathrm{ml}$ volumetric flask and made up with diluent $(500 \mu \mathrm{g} / \mathrm{ml}$ of Ertugliflozin and $7.5 \mu \mathrm{g} / \mathrm{ml}$ of Metformin).

\section{Preparation of Buffer:}

0.1\% OPA Buffer: $1 \mathrm{ml}$ of orthophosphoric acid was diluted to $1000 \mathrm{ml}$ with HPLC grade water.

\section{Method Development:}

Optimized Method: Trials were performed for the method development, and the best peak with least fronting factor was found to be with $\mathrm{RT}=0.736$ min for Ertugliflozin and 1.285 min for Metformin.

\begin{tabular}{lc} 
TABLE 1: OPTIMIZED & CHROMATOGRAPHIC \\
CONDITIONS & Content \\
\hline Parameter & HSS C18 $(100 \times 2.1 \mathrm{~mm}, 1.7 \mu)$ \\
\hline Column & $50 \%$ OPA $(0.1 \%): 50 \%$ \\
Mobile Phase & Acetonitrile \\
& $0.3 \mathrm{ml} / \mathrm{min}$ \\
Flow Rate & $30^{\circ} \mathrm{C}$ \\
Temperature & $0.50 \mu \mathrm{L}$ \\
Injection Volume & Acquity TUV $240 \mathrm{~nm}$ \\
Detection \& Wavelength
\end{tabular}

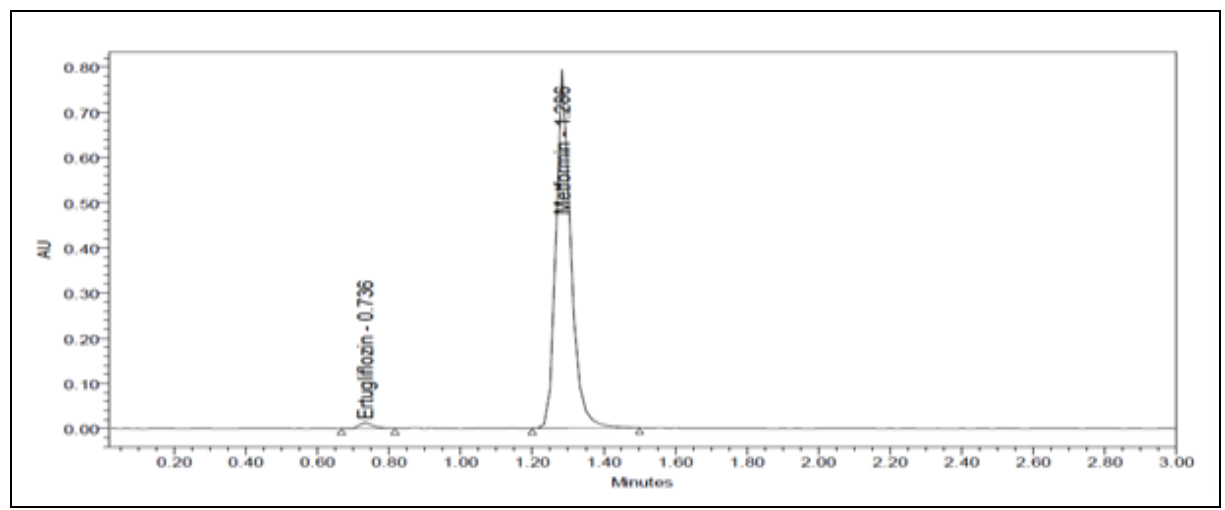

FIG. 2: OPTIMIZED CHROMATOGRAM 
System suitability: According to ICH guidelines, plate count should be more than 2000, tailing factor should be less than 2 and resolution must be more than 2. All the suitable system parameters were passed and were within limits.

TABLE 2: SYSTEM SUITABILITY PARAMETERS FOR ERTUGLIFLOZIN AND METFORMIN

\begin{tabular}{cccccccc}
\hline S. no. & \multicolumn{3}{c}{ Ertugliflozin } & & Metformin & \multirow{2}{*}{ Resolution } \\
\cline { 1 - 6 } Inj & RT(min) & USP Plate Count & Tailing & RT(min) & USP Plate Count & Tailing & \\
\hline 1 & 0.735 & 4339 & 1.89 & 1.284 & 3821 & 1.19 & 6.5 \\
2 & 0.736 & 4376 & 1.83 & 1.284 & 3649 & 1.19 & 6.4 \\
3 & 0.738 & 4297 & 1.89 & 1.288 & 4467 & 1.25 & 6.5 \\
4 & 0.742 & 4987 & 1.77 & 1.292 & 4064 & 1.33 & 6.0 \\
5 & 0.752 & 5022 & 1.55 & 1.299 & 3778 & 1.20 & 5.9 \\
6 & 0.754 & 4938 & 1.39 & 1.301 & 3710 & 1.19 & 6.1 \\
\hline
\end{tabular}

\section{Method Validation:}

Accuracy: Three levels of Accuracy samples were prepared by the standard addition method. Triplicate injections were given for each level of accuracy, and mean \% Recovery was obtained as $100.38 \%$ and $99.81 \%$ for Ertugliflozin and Metformin, respectively.

TABLE 3: RECOVERY STUDIES FOR ERTUGLIFLOZIN AND METFORMIN

\begin{tabular}{ccccccc}
\hline \multirow{2}{*}{$\%$ Concentration } & \multicolumn{3}{c}{ Ertugliflozin } & \multicolumn{3}{c}{ Metformin } \\
\cline { 2 - 6 } & $\mathbf{5 0 \%}$ & $\mathbf{1 0 0 \%}$ & $\mathbf{1 5 0 \%}$ & $\mathbf{5 0 \%}$ & $\mathbf{1 0 0 \%}$ & $\mathbf{1 5 0 \%}$ \\
\hline Trail-I & 100.77 & 100.51 & 100.96 & 99.16 & 100.51 & 100.12 \\
Trail-II & 100.30 & 99.45 & 100.77 & 100.91 & 99.45 & 99.43 \\
Trail-III & 99.86 & 100.34 & 100.47 & 99.97 & 100.34 & 99.50 \\
AVG (\%Recovery) & 100.3 & 100.10 & 100.73 & 100.01 & 99.73 & 99.69 \\
SD & 0.46 & 0.57 & 0.24 & 0.875 & 0.3913 & 0.3809 \\
\%RSD & 0.46 & 0.57 & 0.24 & 0.87 & 0.39 & 0.38 \\
Mean \%Recovery & & 100.38 & & & 99.81 & \\
\hline
\end{tabular}

Precision: From a single volumetric flask of working standard solution six injections were given, and the obtained areas were mentioned above. Average area, standard deviation, and \% RSD were calculated for two drugs. Precision \%
RSD values obtained as $0.8 \%$ and $0.9 \%$ and Intermediate precision values obtained as $0.9 \%$ and $0.6 \%$ respectively for Ertugliflozin and Metformin. As the limit of Precision was less than "2" the system precision was passed in this method.

TABLE 4: SYSTEM PRECISION TABLE OF ERTUGLIFLOZIN AND METFORMIN

\begin{tabular}{ccccc}
\hline S. no. & \multicolumn{2}{c}{ Peak area of Ertugliflozin } & \multicolumn{2}{c}{ Peak area of Metformin } \\
\cline { 2 - 5 } & Precision & Day_Day Precision & Precision & Day_Day Precision \\
\hline 1 & 32315 & 31331 & 1941365 & 1922518 \\
2 & 33046 & 31198 & 1989881 & 1900063 \\
3 & 32805 & 31594 & 1968740 & 1923950 \\
4 & 32912 & 31949 & 1977705 & 1899308 \\
5 & 33017 & 31723 & 1972480 & 1901364 \\
6 & 32965 & 31653 & 1983584 & 1918731 \\
Mean & 32843 & 31575 & 1972293 & 1910989 \\
S.D & 272.5 & 272.0 & 16942.9 & 11910.6 \\
\%RSD & 0.8 & 0.9 & 0.9 & 0.6 \\
\hline
\end{tabular}

TABLE 5: LINEARITY TABLE FOR ERTUGLIFLOZIN AND METFORMIN

\begin{tabular}{cccc}
\hline & Ertugliflozin & & Metformin \\
\hline Conc. $(\boldsymbol{\mu g} / \mathbf{m L})$ & Peak area & Conc. $(\boldsymbol{\mu g} / \mathbf{m L})$ & Peak area \\
\hline 0 & 0 & 0 & 0 \\
1.875 & 7985 & 125 & 464159 \\
3.75 & 15670 & 250 & 993342 \\
5.625 & 23563 & 375 & 1504954 \\
7.5 & 31861 & 500 & 1977084 \\
9.375 & 39210 & 625 & 2478785 \\
11.25 & 46104 & 750 & 2903917 \\
\hline
\end{tabular}


Linearity: Six linear concentrations of Ertugliflozin $(1.875-11.25 \mu \mathrm{g} / \mathrm{ml})$ and Metformin $(125-750 \mu \mathrm{g} / \mathrm{ml})$ were injected in a duplicate manner. Average areas were mentioned above, and

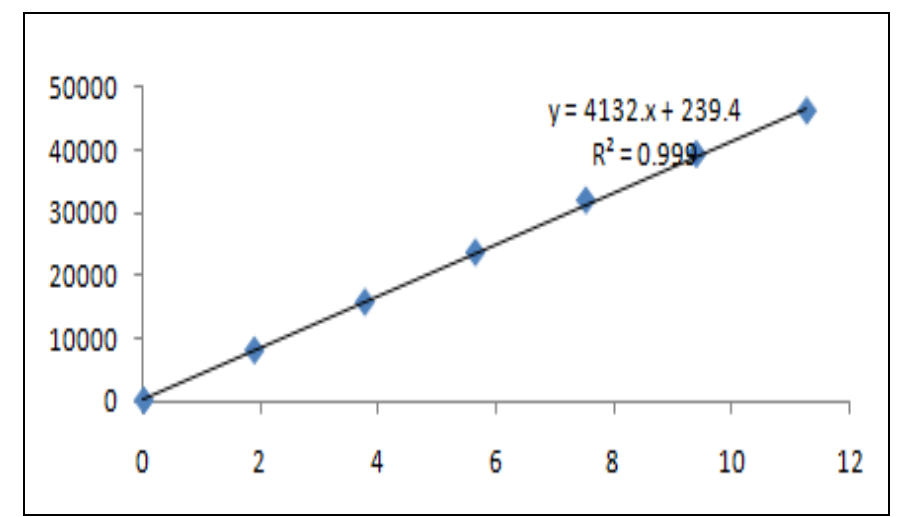

FIG. 3: CALIBRATION CURVE OF ERTUGLIFLOZIN linearity equations obtained for Ertugliflozin were $\mathrm{y}=4132 \cdot \mathrm{x}+239.4$ and of Metformin was $\mathrm{y}=$ 3921.x +4097 . The correlation coefficient obtained was 0.999 for the two drugs.

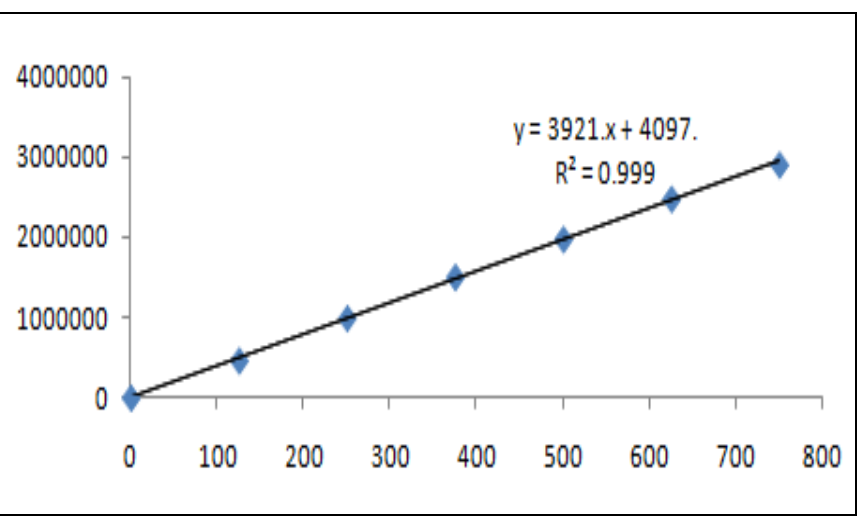

FIG. 4: CALIBRATION CURVE OF METFORMIN

\section{Sensitivity:}

TABLE 6: SENSITIVITY TABLE OF ERTUGLIFLOZIN AND METFORMIN

\begin{tabular}{ccc} 
Molecule & LOD & LOQ \\
Ertugliflozin & 0.02 & 0.18 \\
Metformin & 1.04 & 3.16 \\
\hline
\end{tabular}
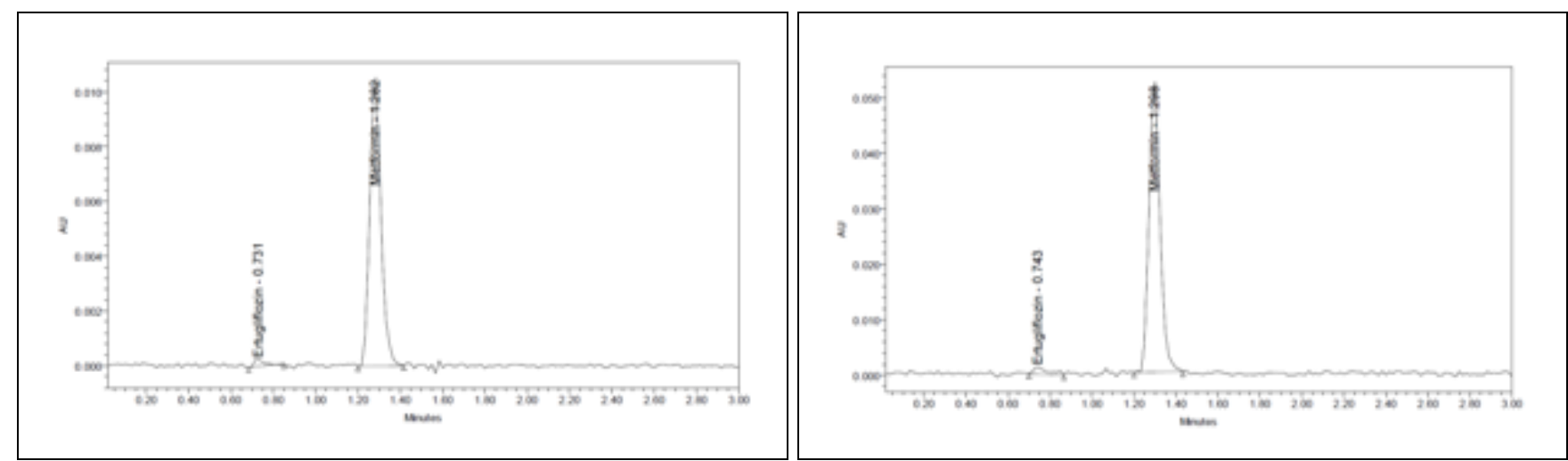

FIG. 5: LOD AND LOQ CHROMATOGRAM OF STANDARD

Robustness: Robustness conditions like Flow minus $(0.20 \mathrm{ml} / \mathrm{min})$, Flow plus $(0.40 \mathrm{ml} / \mathrm{min})$, mobile phase minus $(55: 45 \mathrm{~A})$, mobile phase plus (55B:45A), temperature minus $\left(25{ }^{\circ} \mathrm{C}\right)$ and temperature plus $\left(35{ }^{\circ} \mathrm{C}\right)$ was maintained and samples were injected in a duplicate manner. System suitability parameters were not much affected, and all the parameters were passed. \% RSD was within the limit.

TABLE 7: ROBUSTNESS DATA FOR ERTUGLIFLOZIN AND METFORMIN

\begin{tabular}{cccc}
\hline S. no. & Condition & \%RSD of Ertugliflozin & \% RSD of Metformin \\
\hline 1 & Flow rate (-) $0.2 \mathrm{ml} / \mathrm{min}$ & 0.3 & 0.3 \\
2 & Flow rate $(+) 0.4 \mathrm{ml} / \mathrm{min}$ & 0.9 & 0.3 \\
3 & Mobile phase $(-) 55 \mathrm{~B}: 45 \mathrm{~A}$ & 1.0 & 0.3 \\
4 & Mobile phase $(+) 45 \mathrm{~B}: 55 \mathrm{~A}$ & 0.7 & 0.2 \\
5 & Temperature $(-) 25^{\circ} \mathrm{C}$ & 0.8 & 0.6 \\
6 & Temperature $(+) 35^{\circ} \mathrm{C}$ & 0.2 & 0.8 \\
\hline
\end{tabular}

Degradation Studies: Degradation studies were performed with the formulation, and the degraded samples were injected. Assay of the injected samples was calculated and all the samples passed the limits of degradation. 

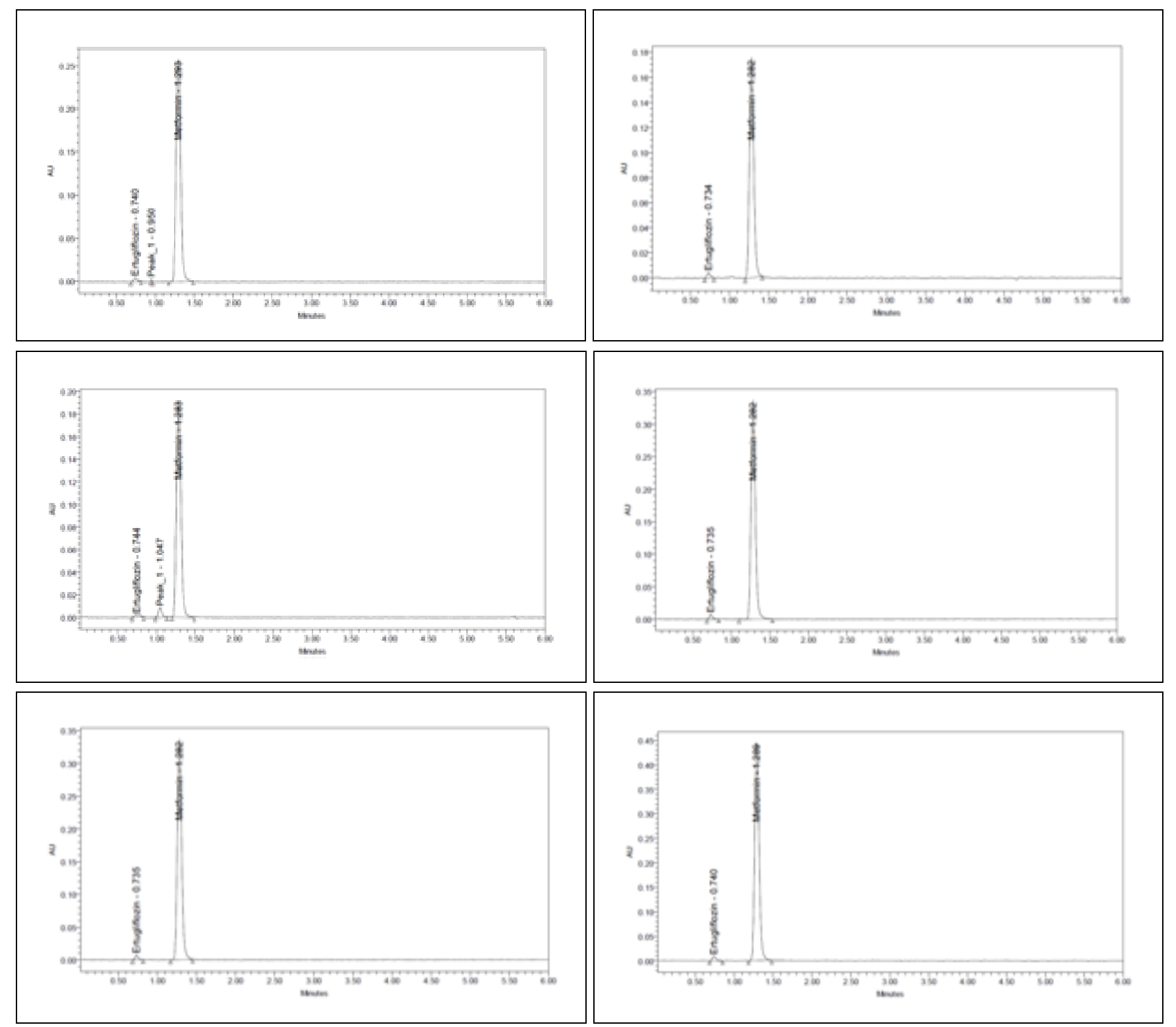

FIG. 6: DEGRADATION CHROMATOGRAMS

TABLE 8: DEGRADATION DATA OF ERTUGLIFLOZIN AND METFORMIN

\begin{tabular}{cccc}
\hline S. no. & Degradation & \multicolumn{2}{c}{ \% Drug Degraded } \\
\cline { 3 - 4 } & Condition & Ertugliflozin & Metformin \\
\hline 1 & Acid & 8.03 & 7.45 \\
2 & Alkali & 6.24 & 6.03 \\
3 & Oxidation & 5.02 & 4.05 \\
4 & Thermal & 3.54 & 2.27 \\
5 & UV & 1.60 & 1.15 \\
6 & Water & 1.60 & 0.51 \\
\hline
\end{tabular}

CONCLUSION: A simple, Accurate, precise method was developed for the simultaneous estimation of the Ertugliflozin and Metformin in Tablet dosage form. The retention time of Ertugliflozin and Metformin was found to be 0.736 min and 1.286 min. \% RSD of the Ertugliflozin and Metformin were and found to be 0.9 and 0.6 respectively. \% Recovery was obtained as $100.38 \%$ and $99.81 \%$ for Ertugliflozin and Metformin, respectively. LOD, LOQ values obtained from regression equations of Ertugliflozin and Metformin were and 0.02, $0.08 \& 1.04,3.16$ respectively. The regression equation of Ertugliflozin is $\mathrm{y}=4132 . \mathrm{x}+239.4$, and $\mathrm{y}=3921$. $\mathrm{x}$ +4097 of Metformin. Retention times were decreased and that run time was decreased, so the method developed was simple and economical that can be adopted in regular Quality control tests in Industries.

ACKNOWLEDGEMENT: The author(s) would like to acknowledge the Department of Pharmaceutical Analysis, Joginpally B.R Pharmacy Campus for providing an institutional research platform and necessary facilities. 


\section{CONFLICTS OF INTEREST: Nil}

\section{REFERENCES:}

1. Miao Z, Nucci G, Amin N, Sharma R, Mascitti V, Tugnait M, Vaz AD, Callegari $\mathrm{E}$ and Kalgutkar AS: Pharmacokinetics, metabolism, and excretion of the antidiabetic agent ertugliflozin in healthy male subjects. Drug Metabolism and Disposition 2013; 41(2): 445-56.

2. Amin NB, Wang $X$ and Mitchell JR: Blood pressure-lowering effect of the sodium glucose co-transporter-2 inhibitor ertugliflozin, assessed via ambulatory blood pressure monitoring in patients with type 2 diabetes and hypertension. Diabetes Obesity and Metabolism 2015; 17: 805-08.

3. Terra SG, Focht K and Davies M: Phase III, efficacy and safety study of ertugliflozin monotherapy in people with type 2 diabetes mellitus inadequately controlled with diet and exercise alone. Diabetes Obesity and Metabolism 2017; 19: 721-28.

4. Cinti F, Moffa S, Impronta F, Cefalo CM, Sun VA and Sorice GP: Spotlight on ertugliflozin and its potential in the treatment of Type 2 diabetes: Evidence to date. Drug Design, Developmentand Therapy 2017; 11: 2905-19.

5. Chhetri HP, Thapa P and Van Schepdael A: Simple HPLC-UV method for the quantification of metformin in human plasma with one step protein precipitation. Saudi Pharmaceutical Journal 2014; 22: 483-87.

6. Eva T, Leonard D and Gezim B: Ion-pair HPLC method for the quantification of metformin in human urine. Journal of Applied Bioanalysis 2016; 2: 16-24.

7. Wang YW, He SJ, Feng X, Cheng J, Luo YT and Tian L: Metformin: A review of its potential indications. Drug Design, Development and Therapy 2017; 11: 2421-9.

8. Psrcnpv D, Rao AL and Dinda SC: Simultaneous determination of metformin and vildagliptin in solid dosage form by stability indicating RP-HPLC method. International Research J of Pharmacy 2013; 4: 122-28.

9. Sowjanya P: RP-HPLC Method Development of Metformin in Pharmaceutical Dosage Form Research \& Reviews: Journal of Pharmaceutical Analysis 2015; 4(4): 9-20.

10. Goud VM and Nidhi N: Stability indicating development and validation for simultaneous estimation of bromohexine and cephalexin RP-HPLC method. International Journal of Pharma Sciences 2017; 7(6): 1873-76.

11. Goud VM, Swamy LK, Prasanna DS and Rani MS: RPHPLC method development and validation for Simultaneous Determination of Metformin and Canagliflozin. Frontier Journal of Pharmaceutical Sciences and Research 2018; 1(1): 14-19.

12. Harshalatha $\mathrm{P}$, Chandrasekhar $\mathrm{KB}$ and Chandrasekhar MV: A novel RP-HPLC method for simultaneous determination of Ertugliflozin and Sitagliptin in bulk and tablet dosage form. International Journal of Research in Pharmaceutical Sciences 2018; 9(3): 1042-50.

13. Rao PV: A new stability indicating RP-HPLC method for simultaneous estimation of Ertugliflozin and Sitagliptin in Bulk and pharmaceutical dosage form its validation as per ICH Guidelines. Indo American Journal of Pharmaceutical Sciences 2018; 5(4): 2616-27.

14. Nizami T, Shrivastava B and Sharma P: Analytical method development and validation for simultaneous estimation of Ertugliflozin and Metformin in tablet dosage form by RPHPLC method. International Journal of Pharmacy \& Life Sciences 2018: (7): 5854-59.

15. ICH Harmonised Tripartite Guideline. Validation of analytical procedures, Text and methodology, Q1 R2. International Conference on Harmonization 2005, 1-13.

16. ICH Harmonised Tripartite Guideline, Stability Testing of New Drug Substances and Products, Q1A (R2). International Conference on Harmonization 2003, 1-18.

How to cite this article:

Goud VM and Swapna G: Stability indicating method development and validation for the estimation of ertugliflozin and metformin in bulk and pharmaceutical dosage form by ultra performance liquid chromatography. Int J Pharm Sci \& Res 2020; 11(1): 173-78. doi: 10.13040/IJPSR.0975-8232.11(1).173-78.

All @ 2013 are reserved by the International Journal of Pharmaceutical Sciences and Research. This Journal licensed under a Creative Commons Attribution-NonCommercial-ShareAlike 3.0 Unported License.

This article can be downloaded to Android OS based mobile. Scan QR Code using Code/Bar Scanner from your mobile. (Scanners are available on Google Playstore) 